\title{
A REUTILIZAÇÃO DE RECIPIENTES PLÁSTICOS DE USO DOMÉSTICO NA CONFECÇÃO DE SACOLAS
}

\author{
Luciane da Silva Vicente', Elza de Fátima Bedani² \\ ${ }^{1}$ Professora das redes Municipal e Estadual de São Paulo; Pós-graduanda em Educação Ambiental na UNG - \\ lusivisv@hotmail.com \\ ${ }^{2}$ Professora e Pesquisadora da Universidade Guarulhos - Graduação e Pós-Graduação - ebedani@prof.ung.br
}

\section{RESUMO}

Os resíduos sólidos domésticos são uma fonte potencial de problemas ambientais. Ao serem descartados em lugares inapropriados, muitas vezes entopem as galerias de águas pluviais ocasionando nas épocas de chuvas intensas, enchentes e outros transtornos como alagamentos menos invasivos. Materiais plásticos, como garrafas PET e sacolas distribuídas no comércio em geral, são os maiores vilões entre os resíduos sólidos de um modo geral, pois levam anos para se decompor na natureza e criam uma espécie de barreira para o fluxo de água. Diante do uso constante e do descarte inadequado desses materiais se faz necessário uma intervenção para solucionar - em parte - esse problema ambiental. Esse estudo tem por objetivo propor uma alternativa para minimizar o problema em questão: a transformação dos resíduos plásticos de uso doméstico em sacolas de uso diversificado, que além práticas podem substituir - facilmente sacolas plásticas nas compras cotidianas.

Palavras-chave: meio ambiente, resíduos sólidos, recipientes plásticos, reutilização, sacolas.

\section{ABSTRACT}

Domestic solid wastes are a potential source of environmental problems. When disposed in inappropriate places, they often clog storm sewer leading in times of heavy rains, floods and other disorders such floods less invasive. Plastic materials as PET bottles and bags distributed in commerce in general, are the greatest villains of solid waste, they take years to decompose in nature and create a sort of barrier to the flow of water. Given the constant use and improper disposal of these materials is necessary to solve an intervention - in part - this environmental problem. This study aims to propose an alternative to minimize the problem at hand: the transformation of household waste in plastic bags of various purpose, besides that practices can replace - easily - in plastic bags everyday purchases.

Keywords: environment, solid waste, plastic containers, reusing, bags. 


\section{INTRODUÇÃO}

A consciência sobre os problemas ambientais tem crescido e, com isto, a necessidade de revisão dos valores do modelo de desenvolvimento da atualidade.

O consumo exacerbado de bens por meio do poder aquisitivo da população, bem como pela influência midiática, faz com que haja uma produção excessiva de resíduos sólidos plásticos e assim os impactos ambientais provenientes desse consumo também cresçam vertiginosamente.

Este estudo traz novos direcionamentos como uma alternativa de enfrentamento do problema dos resíduos sólidos plásticos, conseqüentemente, a abertura de novas perspectivas econômicas, sociais e ambientais conscientes para a sociedade.

Para ratificar este pensamento Aguiar (apud Cookson, 1992) menciona:

existe a necessidade de viabilizar reciclagem dos materiais plásticos descartados no lixo doméstico, dada a tendência das condições econômicas e culturais atuais indicarem o aumento da produção de lixo, e em particular do descarte do material plástico.

Compartilhando esse conceito este trabalho visa ao desenvolvimento sustentável, tanto em relação ao consumo de bens, quanto ao seu descarte. Ainda valendo-se da definição dos " $3 R^{\prime}$ (reduzir, reutilizar e reciclar) propomos que a produção artesanal de sacolas feitas de resíduos plásticos de uso domésticos atinja esses objetivos, bem como de propiciar como opção, capacitação profissional de pessoas sem vínculos empregatícios e a geração de renda familiar, como uma proposta social além de ambiental.

\section{OBJETIVOS}

- Implementar procedimentos de reutilização de recipientes plásticos de uso doméstico, de modo a obter geração de renda e reduzir a quantidade destes resíduos a serem dispensados no ambiente.

- Apresentar de forma clara e objetiva uma proposta para reutilização de recipientes plásticos de uso doméstico;

- Reduzir a quantidade de recipientes plásticos a ser dispensados meio ambiente;

- Gerar renda;

- Propor formas de enfrentamento para as questões que tangem problemas ambientais.

\section{RESÌDUOS SÓLIDOS}

\subsection{Definição de resíduos sólidos}

Normalmente os autores de publicações sobre resíduos sólidos se utilizam indistintamente dos termos "lixo" e "resíduos sólidos". Resíduo sólido ou simplesmente "lixo" é todo material sólido ou semi-sólido indesejável e que necessita ser removido por ter sido considerado inútil por quem o descarta em qualquer recipiente destinado a este ato.

Há de se destacar, no entanto, a relatividade da característica inservível do lixo, pois aquilo que já não apresenta nenhuma serventia para quem o descarta, para outro pode se tornar matéria-prima para um novo produto ou processo. Nesse sentido, a idéia do reaproveitamento do lixo é um convite à reflexão do próprio conceito clássico de resíduos sólidos. É como se o lixo pudesse ser conceituado como tal somente quando da inexistência de mais alguém para reivindicar uma nova utilização dos elementos então descartados (MONTEIRO et al., 2001). 


\subsection{Características dos Resíduos sólidos}

As características do lixo podem variar em função de aspectos sociais, econômicos, culturais, geográficos e climáticos, ou seja, os mesmos fatores que também diferenciam as comunidades entre si e as próprias cidades.

A Tabela 1 expressa a variação das composições do lixo em alguns países, deduzindo-se que a participação da matéria orgânica tende a se reduzir nos países mais desenvolvidos ou industrializados, provavelmente em razão da grande incidência de alimentos semi-preparados disponíveis no mercado consumidor:

\begin{tabular}{|c|c|c|c|c|}
\hline \multicolumn{5}{|c|}{ COMPOSIÇÃO GRAVIMÉTRICA DO LIXO DE ALGUNS PAÍSES (\%) } \\
\hline Composto & Brasil & Alemanha & Holanda & EUA \\
\hline Matéria orgânica & 65,00 & 61,2 & 5,30 & 35,60 \\
\hline Vidro & 3,00 & 10,40 & 14,50 & 8,20 \\
\hline Metal & 4,00 & 3,80 & 6,70 & 8,70 \\
\hline Plástico & 3,00 & 5,80 & 6,00 & 6,50 \\
\hline Papel & 25,00 & 18,80 & 22,50 & 41,00 \\
\hline
\end{tabular}

Tabela 1 - Variação das composições do lixo em alguns países (Monteiro et al, 2001).

\subsection{Embalagens plásticas}

A principal matéria-prima dos plásticos comerciais é a Nafta, uma das frações provenientes do craqueamento do petróleo que, por sua vez, é um recurso não renovável. Os plásticos, de um modo geral, são um pequeno, mas significativo componente do fluxo de geração de resíduos.

Os polímeros destinados à fabricação de embalagens possibilitaram a substituição de matérias-primas como: madeira, ossos, lã, bambu, marfim, casco de tartaruga, entre outras, cuja exploração poderia comprometer a manutenção de representantes de espécies animais e vegetais (XAVIER 2006, apud TOENSMEIER, 1993). As embalagens evoluíram de uma pequena gama de recipientes rígidos e pesados feitos basicamente de produtos naturais para outros mais leves, podendo ser flexíveis, semi-rígidos ou rígidos, confeccionados com menos material, produzidos com maior eficiência e utilizando materiais especializados. Comercialmente existem diversos tipos de plásticos que, em função de fatores estéticos, econômicos e funcionais determinam a seleção da embalagem para uma determinada aplicação (XAVIER 2006, apud MICHAELI, 1995).

Em função de suas propriedades, o PET vem sendo utilizado, prioritariamente, na fabricação de garrafas para o acondicionamento de bebidas gasosas, filmes de poliéster para embalagens, além de fiação para o setor de vestuário. Mesmo representando apenas $3 \%$ do total de mercado de plásticos, ou seja, $10 \%$ do mercado de plásticos destinado ao setor de embalagens seu mercado é altamente especializado, sendo destinado basicamente ao setor de bebidas carbonatadas (XAVIER 2006, apud DUCHIN E LANGE, 1998).

Outra contribuição importante que a cadeia produtiva pode incentivar é a produção de embalagens com número menor de resinas diferentes, o desenho de projetos que facilitem a separação de componentes das embalagens com resinas diferenciadas, evitando-se, sempre que possível, o uso de embalagens multicamadas, adesivos, aditivos e rótulos (XAVIER 2006, apud DENT, 1999 e SANTOS et al, 2004). 
Considerando-se que o ponto crítico para as legislações locais é a distribuição de responsabilidades pela redução dos resíduos de embalagens plásticas, pode-se verificar na cadeia produtiva desse setor 4 elementos: o produtor da matéria prima; o processador; o envasador e o atravessador (XAVIER 2006, apud TOMBS, 1999). Geralmente, devido a maior acessibilidade dos atravessadores ao consumidor final, pode lhes ser atribuído um maior percentual de responsabilidade para que os objetivos impostos pela legislação sejam atingidos. Da mesma forma, os envasadores também apresentam grande potencial de responsabilidade por estarem também próximos aos consumidores e ditarem o design e especificações das embalagens (XAVIER, 2006).

\section{METODOLOGIA}

\subsection{Materiais}

- Oito potes de amaciante (embalagem de 2 litros);

- Um furador de papel (adaptado);

- Um cone de linha de polipropileno;

- Tesoura;

- Agulha para crochê no 4;

- Agulha de bordado;

- Guilhotina, régua e caneta.
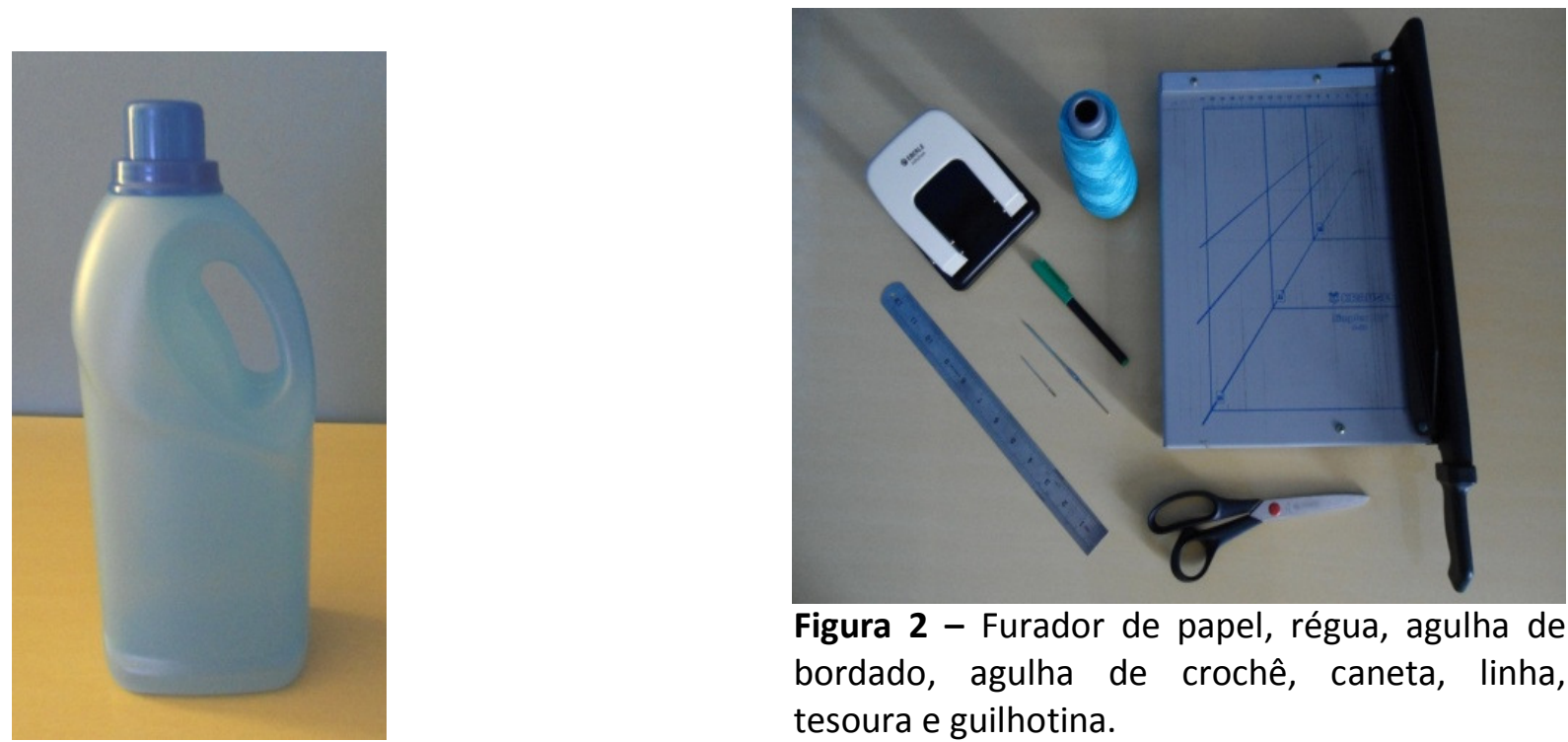

Figura 2 - Furador de papel, régua, agulha de bordado, agulha de crochê, caneta, linha, tesoura e guilhotina.

Figura 1 - Pote de amaciante.

\subsection{Métodos}

\subsubsection{Corte e Obtenção das Peças}

- Cortar os potes nos quatro cantos; 


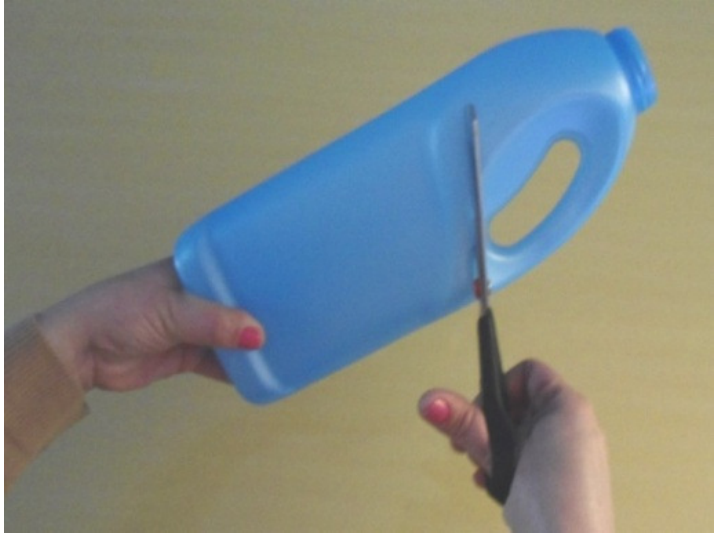

Figura 3 - Corte da frente do pote de amaciante.

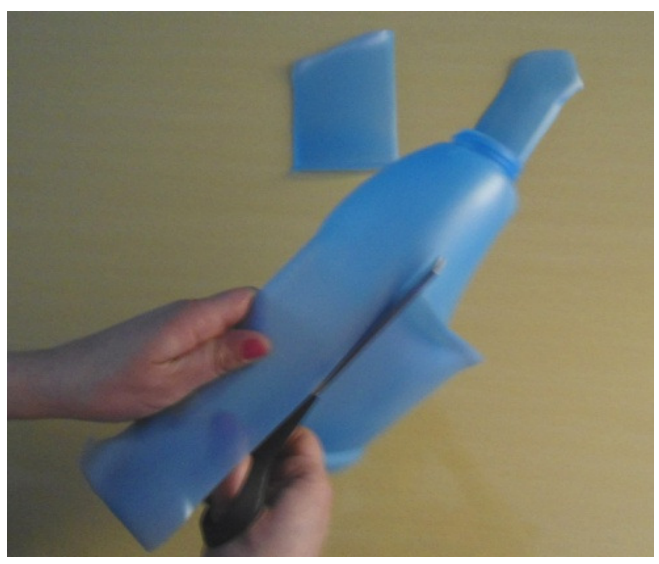

5 - Corte da lateral maior do pote de amaciante.

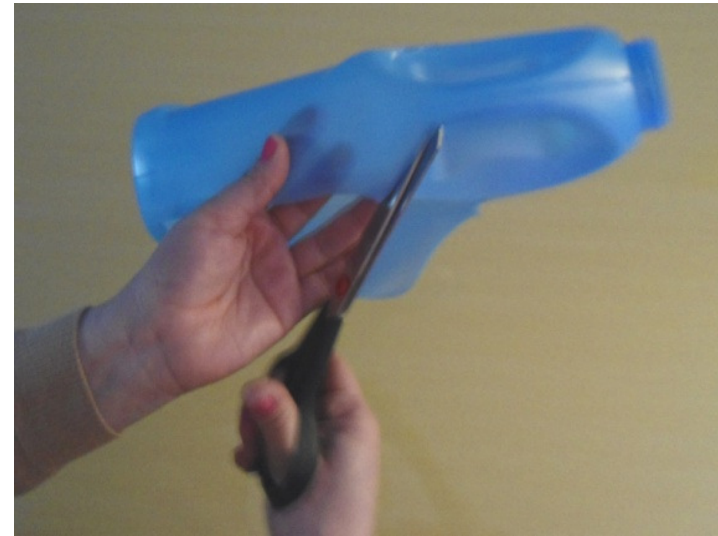

Figura 4 - Corte da lateral menor do pote de amaciante.

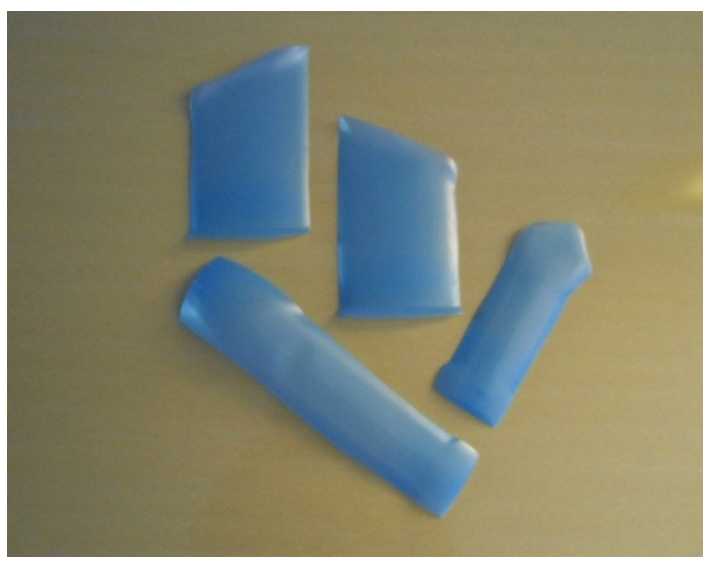

Figura 6 - Partes obtidas do corte do pote de amaciante.

- De cada pote cortado deverá obter duas partes de igual tamanho e duas diferentes;

- Na guilhotina, recortar cada uma das quatro partes em tamanhos iguais de acordo com sua forma; 


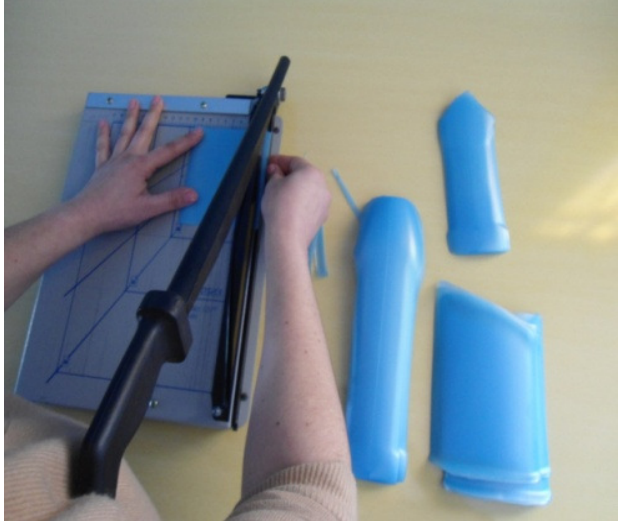

das peças.

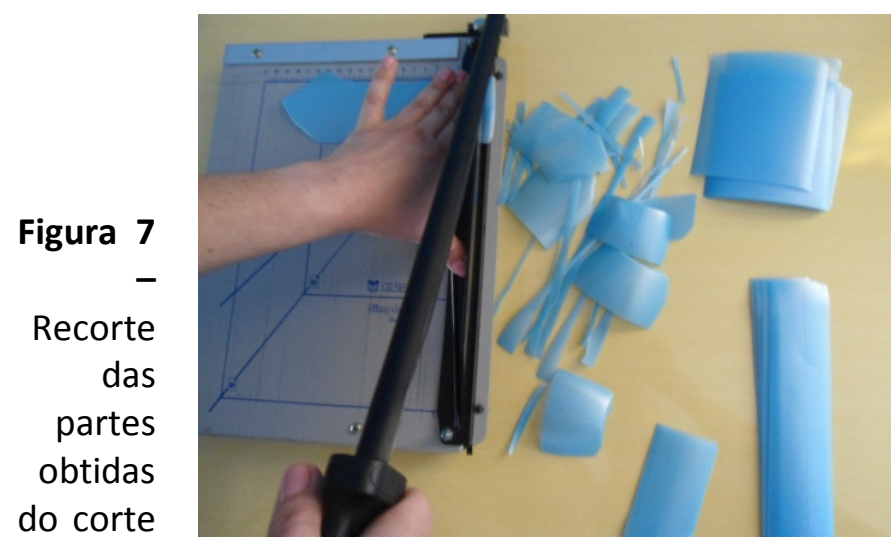

Figura 8 - Partes obtidas do recorte das peças.

As peças deverão ser recortadas de modo a obter as seguintes medidas:

- Frente e costas - 16 peças ( $9 \mathrm{~cm} \times 11,5 \mathrm{~cm}$ cada);

- Laterais -4 peças $(23 \mathrm{~cm} \times 4 \mathrm{~cm}$ cada);

- Fundo - 2 peças ( $20 \mathrm{~cm} \mathrm{X} 4 \mathrm{~cm}$ cada) e 2 peças ( $16 \mathrm{~cm} \mathrm{X} 4 \mathrm{~cm}$ cada).

- Alças-( 1,8 mm X $28 \mathrm{~cm}$ cada).

As alças deverão ser cortadas manualmente, utilizado a régua e a caneta.

- Reservar uma das partes - a lateral mais longa (sem cortar na guilhotina) para fazer as alças;

- Cortar a peça que formará a alça ao meio;

- Medir, riscar e cortar manualmente;

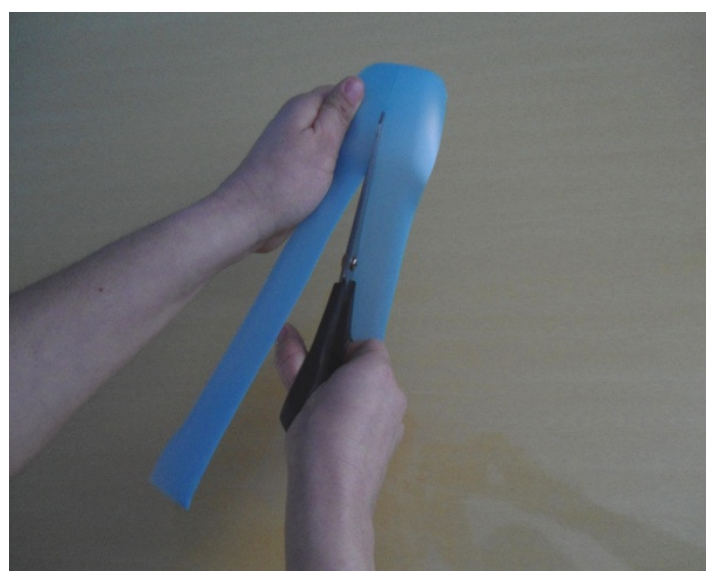

Figura 9 - Preparação das alças

- Arredondar os cantos das alças;

- Arredondar os cantos das demais peças;

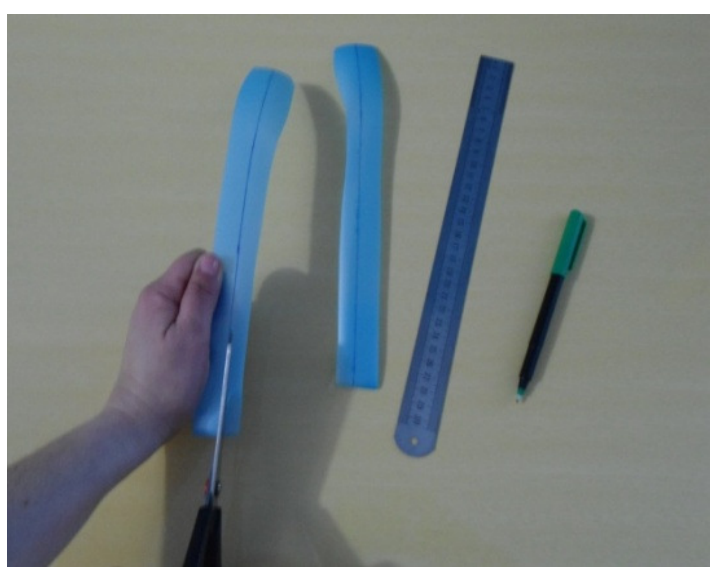

Figura 10 - Corte manual das Alças 


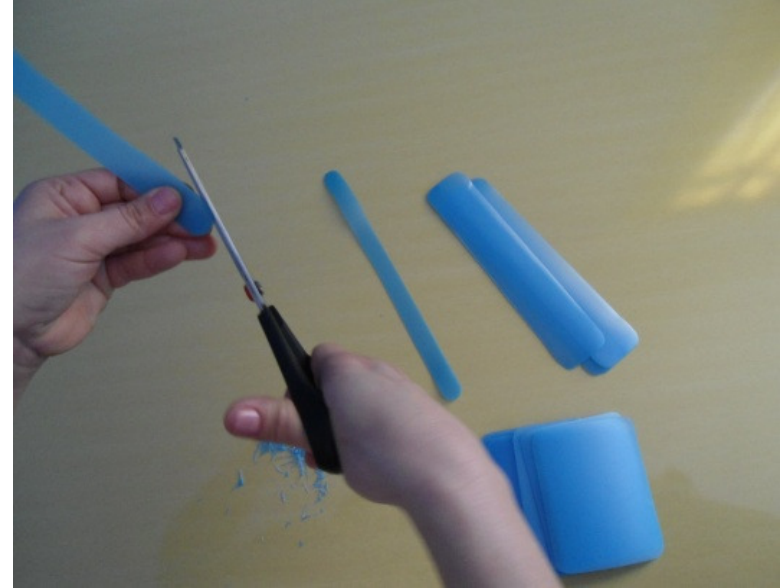

Figura 11 - Arredondamento do canto das alças.

\subsubsection{Adaptação do Furador de Papel}

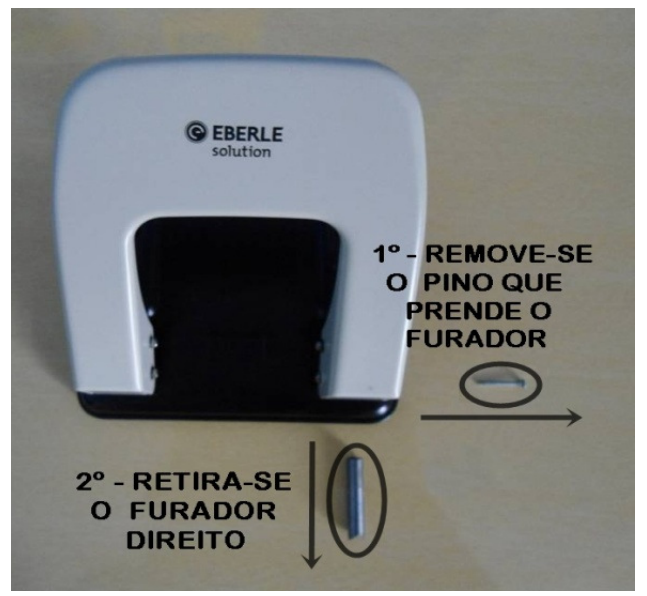

Figura 13 - Retirada do pino e do furador do lado direito.

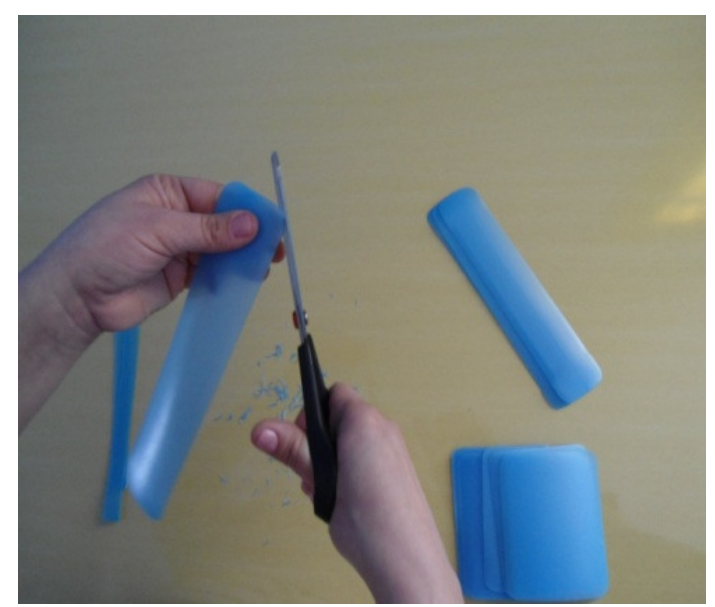

Figura 12 - Arredondamento dos cantos das peças.

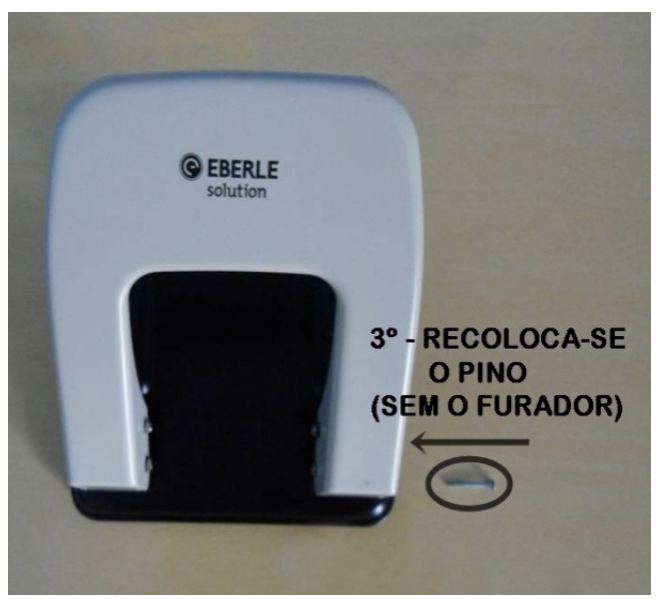

Figura 14 - Recolocação do pino do lado direito.

\subsubsection{Perfuração da Peças}

Utilizar o furador de papel adaptado para furar as peças; 


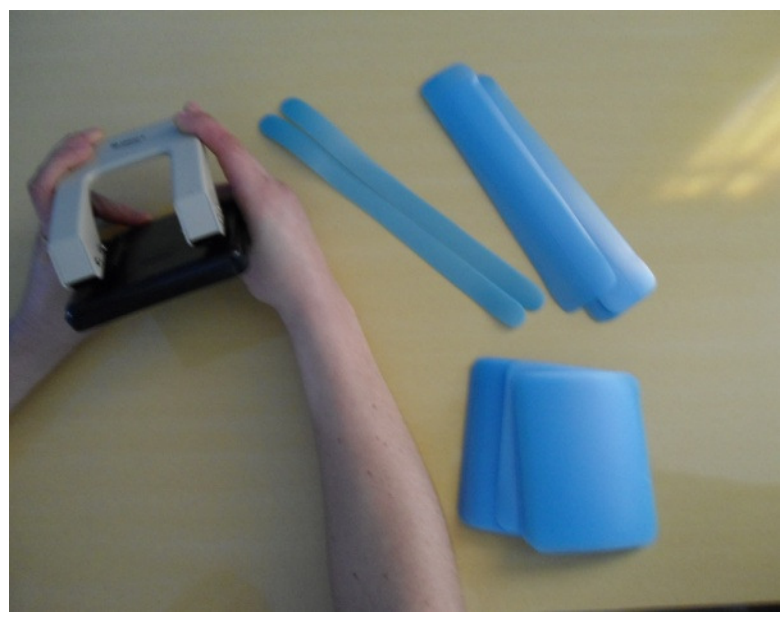

Figura 15 - Furador de papel e peças.

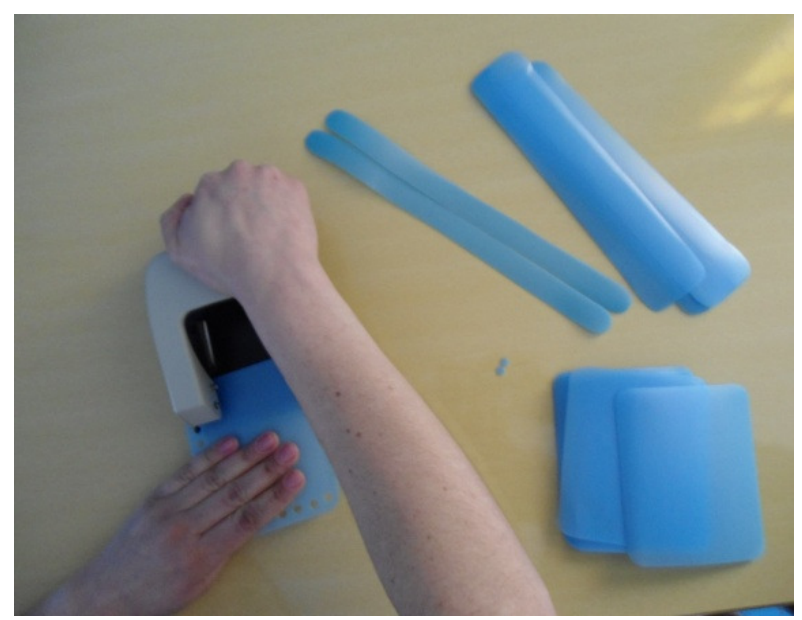

Figura 16 - perfuração das peças com arredondamento finalizado.

- Furar em volta de cada uma das peças, deixando um espaço de aproximadamente $0,5 \mathrm{~mm}$ entre a borda e a circunferência do furo da peça.

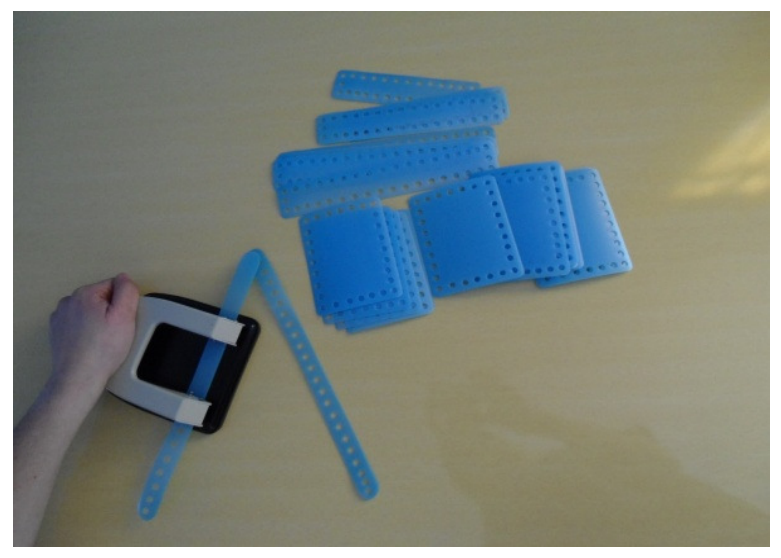

Figura 17 - Perfuração das alças.

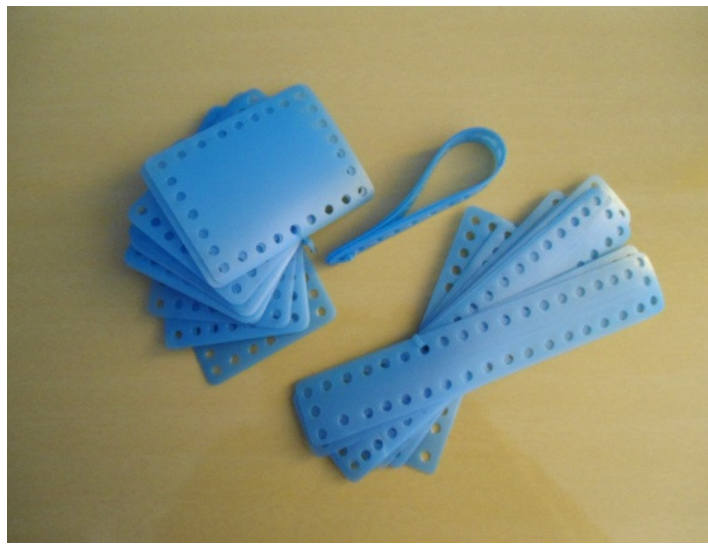

Figura 18 - Perfuração das peças finalizada.

\subsubsection{Dimensões e Esquema de Montagem}

A sacola a ser confeccionada nestes moldes, apresentará as seguintes dimensões: $23 \mathrm{~cm}$ de altura, $36 \mathrm{~cm}$ de largura e $8 \mathrm{~cm}$ de profundidade.

- As peças deverão ser agrupadas de acordo com o esquema abaixo: 


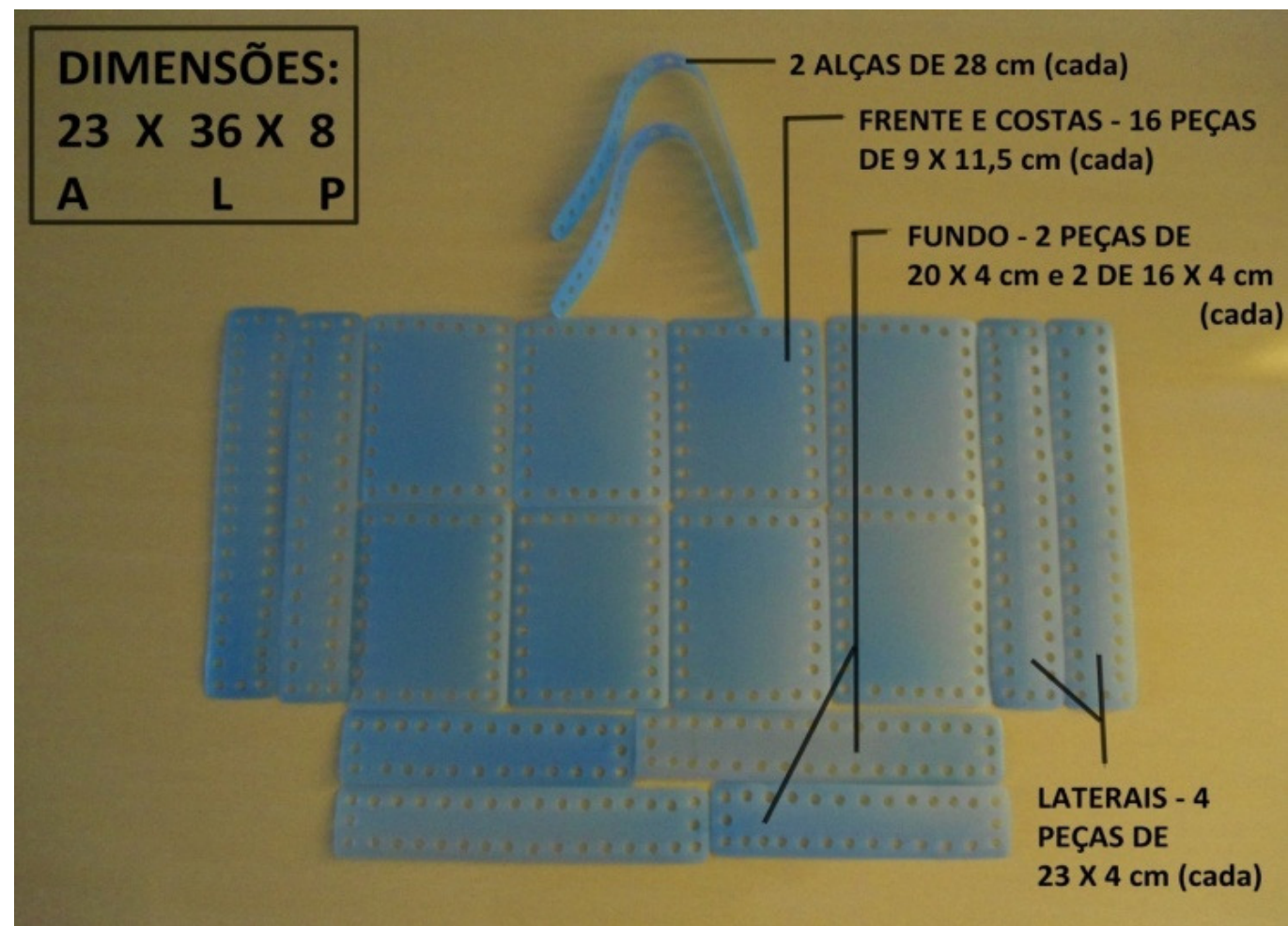

Figura 19 - Esquema de montagem das peças

\subsubsection{Montagem da Sacola}

- Começar pelas peças que formarão o fundo da sacola;

- Contornar cada uma das peças com três pontos baixos de crochê em cada furo;

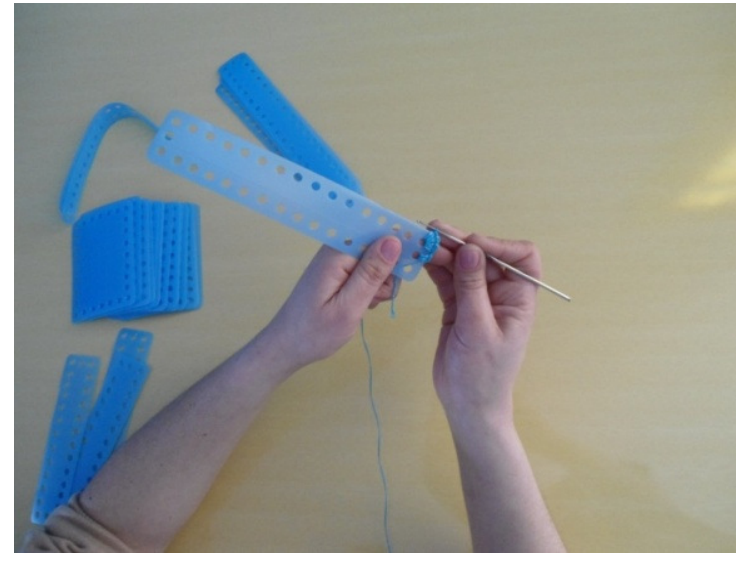

Figura 20 - Contornado a peça com crochê.

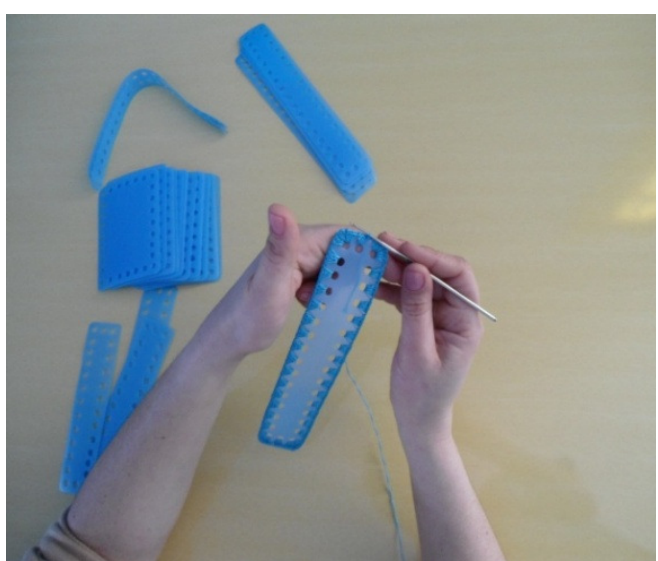

Figura 21 - Finalização da primeira peça contornada com crochê.

- Emendar a primeira peça contornada com crochê com outra peça parcialmente contornada com crochê para formar a metade do fundo. 


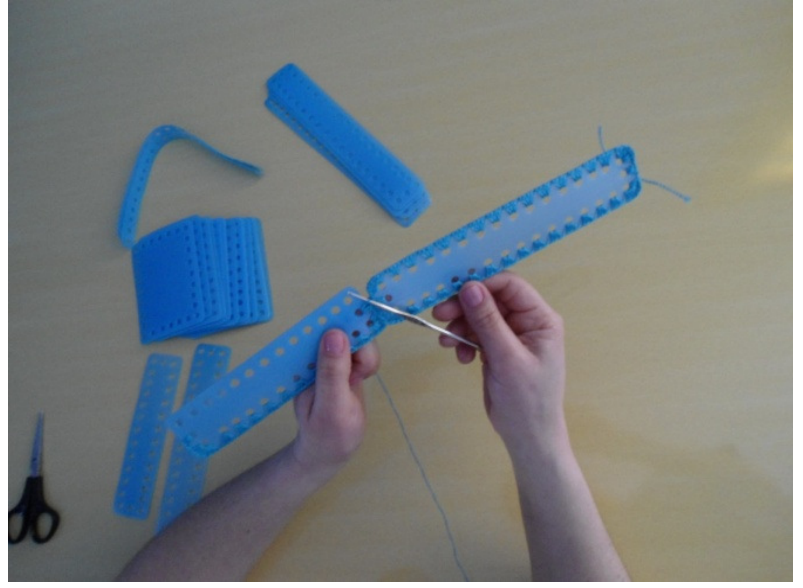

Figura 22- Contornando e emendando a segunda peça com crochê que formará o fundo.

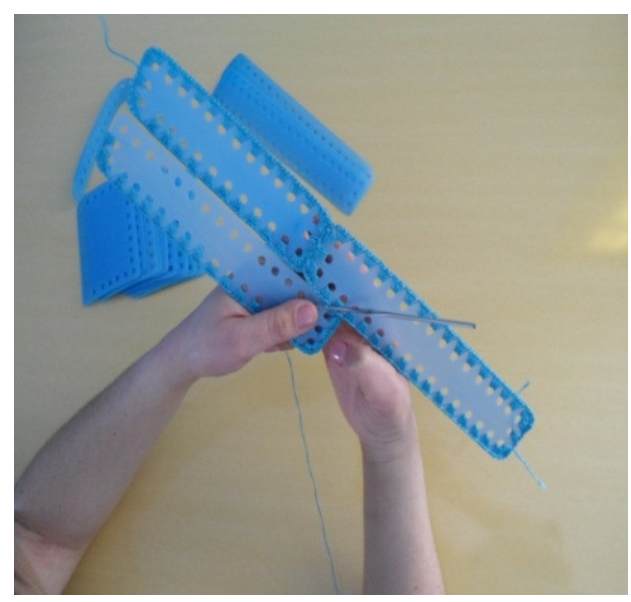

Figura 23 - Contornando e emendando a terceira peça com crochê que formará o fundo.

- Emendar a terceira peça parcialmente contornada com crochê, procedendo da mesma forma para emendar a quarta peça;

- Contornar e pregar as peças da parte inferior da frente com crochê;
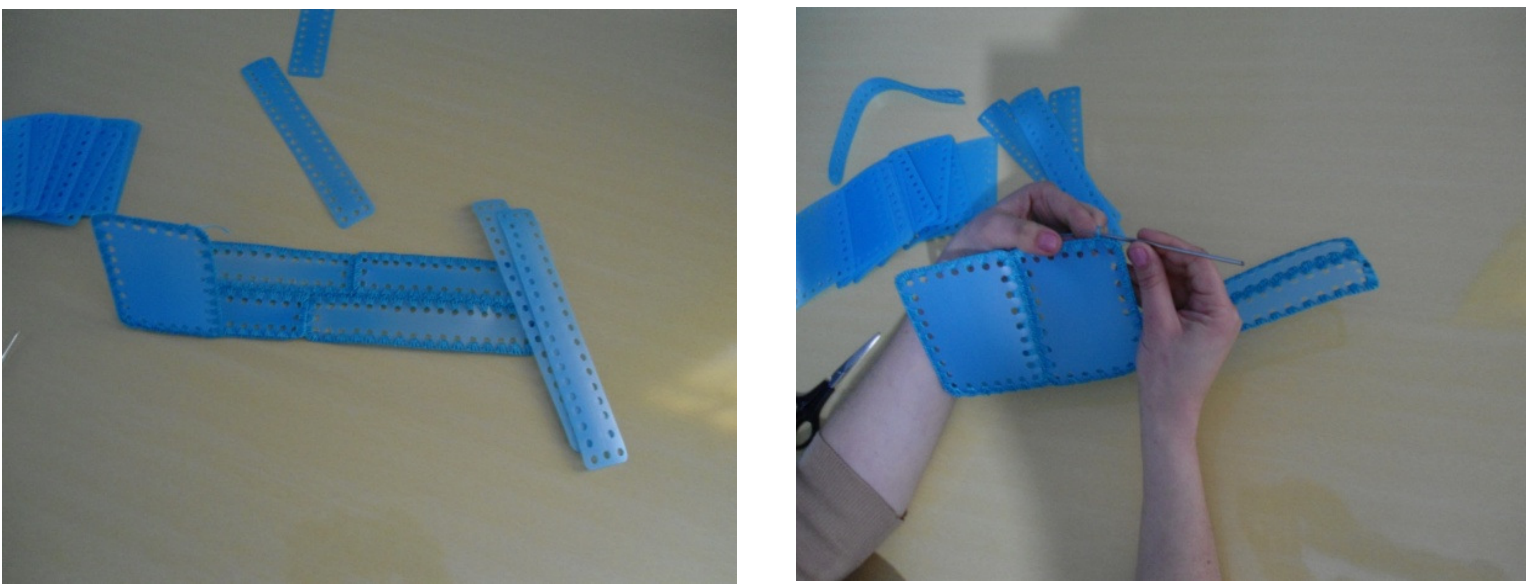

Figura 24- Finalização do fundo e início primeira peça da frente inferior.

Figura 25 - Contornado e emendando a segunda peça da frente inferior. 

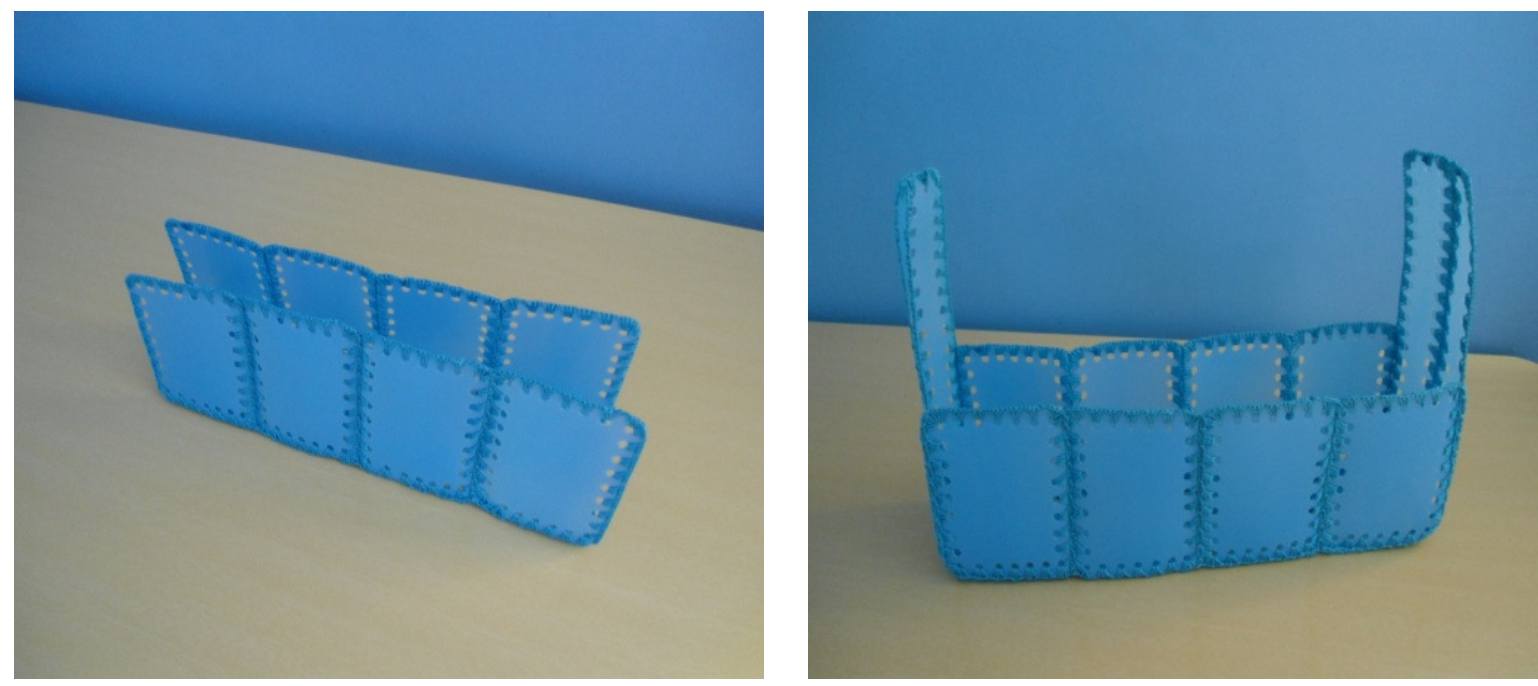

Figura 26- Finalização da frente e costas Figura 27-Finalização das laterais. inferiores.

- Pregar as peças das laterais com crochê;

- Pregar as peças da frente e costas superiores com crochê.
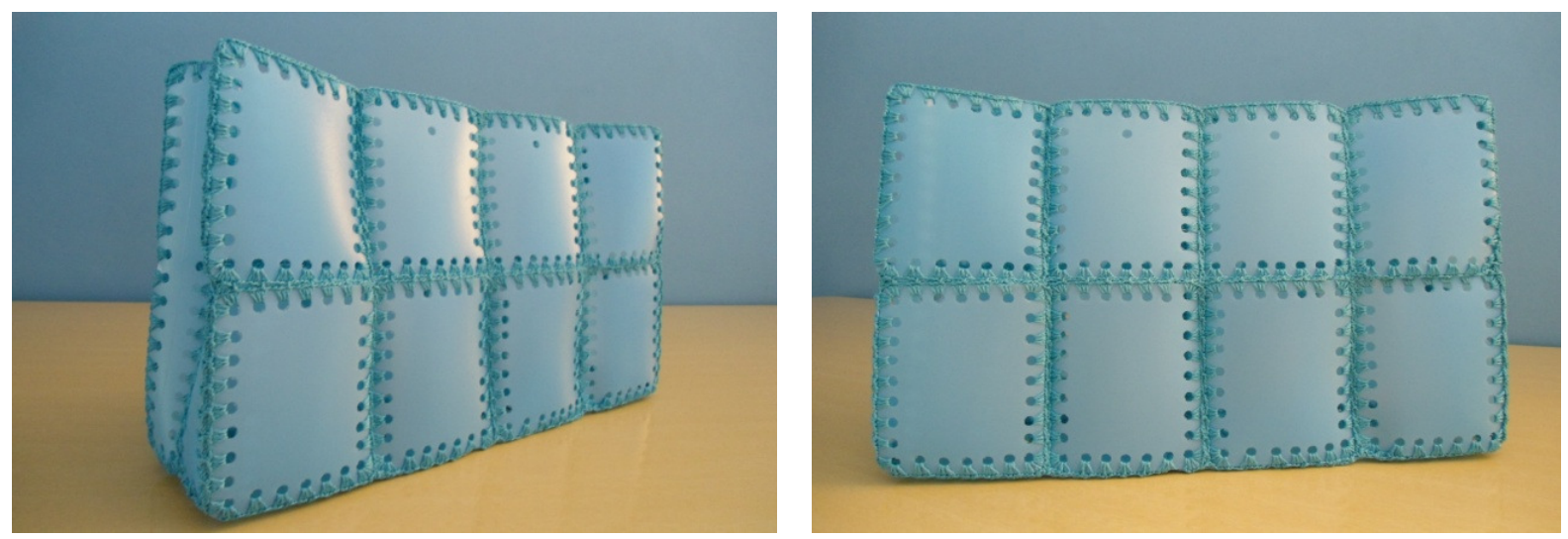

Figura 28- Finalização da frente e costas superiores.

Figura 29 - Visualização da montagem concluída. 


\subsubsection{Aplicação das Flores}

- Confeccionar duas flores de crochê;

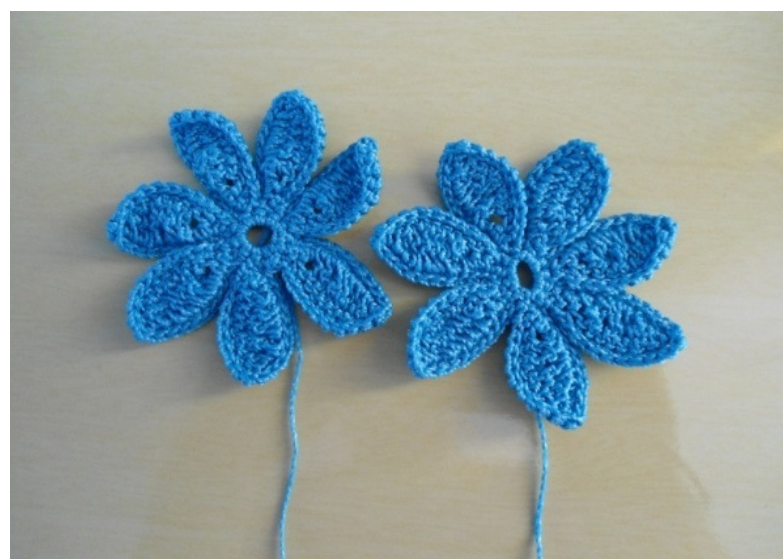

Figura 30- Flores confeccionadas de crochê.

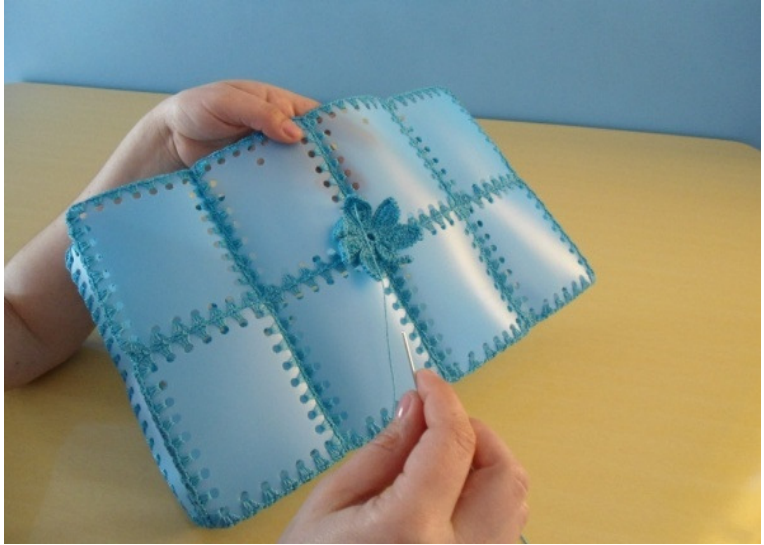

Figura 31 - Pregando as flores.

- Pregar as flores no centro da frente e das costas da sacola, utilizando a agulha de bordado.

\subsubsection{Montagem das Alças}

- Pregar as alças contornando-as com três pontos baixos de crochê em cada furo;

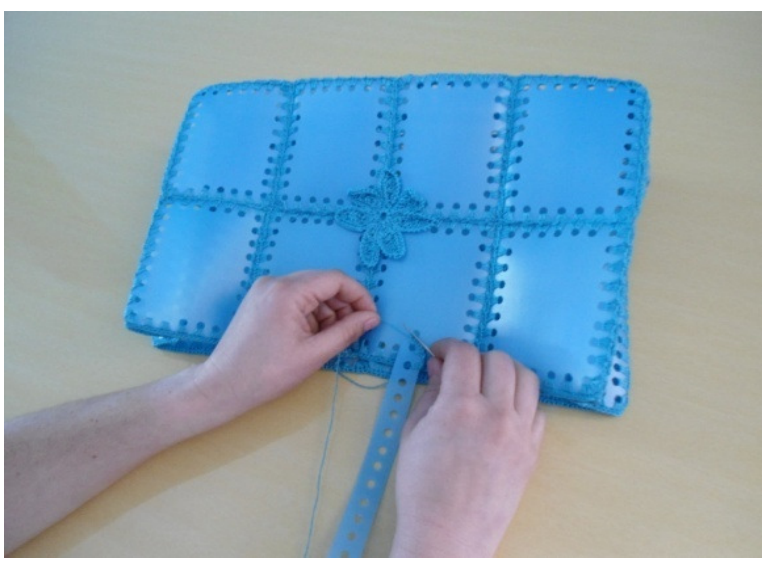

Figura 32- Pregando a primeira alça.

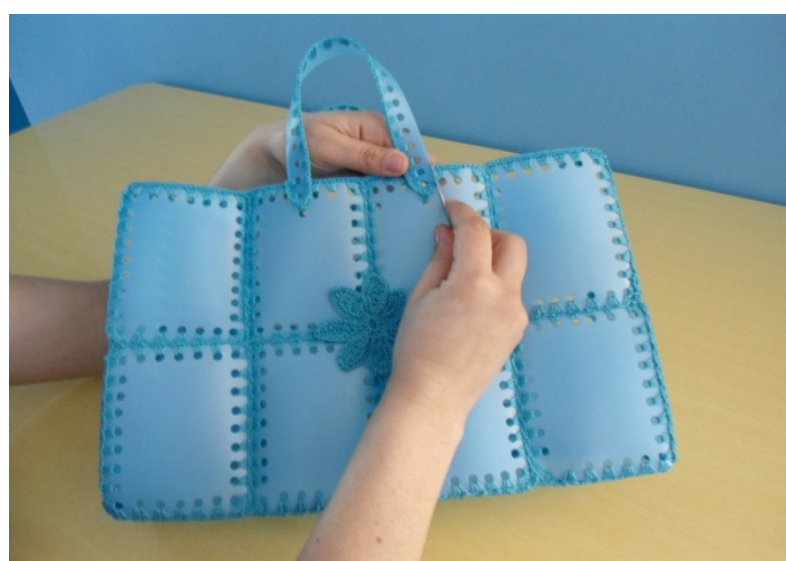

Figura 33- Pregando a segunda alça. 


\section{Monografias Ambientais $\quad e$-ISSN: 2236-1308}

\subsection{Resultado}

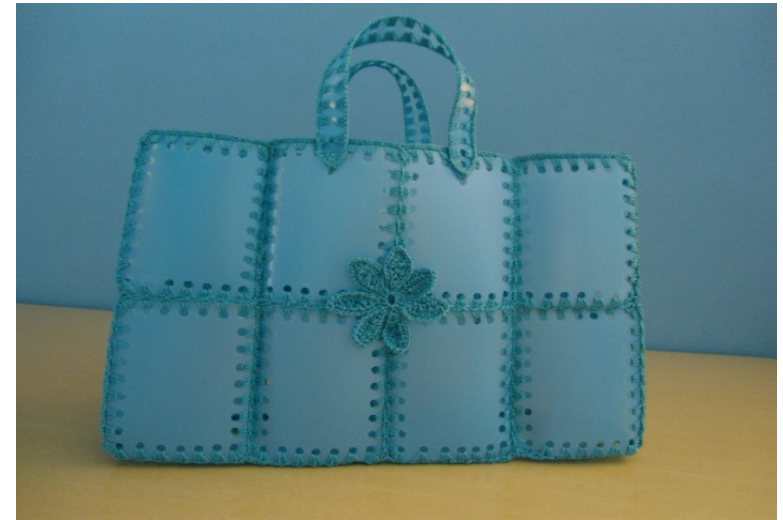

Figura 34 - Sacola concluída vista de frente

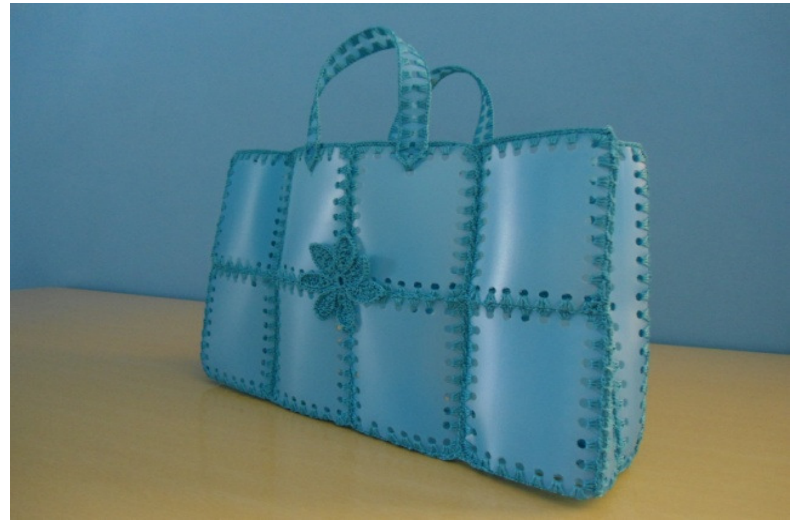

Figura 35 - Sacola concluída vista de perfil

\section{CONSIDERAÇÕES FINAIS}

O material utilizado nesta proposta de reutilização de recipientes plásticos foi basicamente embalagens de amaciante de roupas, porém podem ser reutilizados também, para este fim outros recipientes, como, garrafas PET, potes de shampoo, de alvejante de roupas, de água sanitária, entre outros. A reutilização destes materiais para a confeç̧ão de sacolas além de reduzir o acúmulo destes resíduos no ambiente, proporciona novas perspectivas econômicas, sociais e ambientais para a sociedade.

\section{REFERÊNCIAS}

AGUIAR, ALEXANDRE; JUNIOR, PHILIPPI ARLINDO. Reciclagem de Plásticos de Resíduos Domésticos: Problemas e Soluções, Faculdade de Saúde Pública da USP Departamento de Saúde Ambiental, (s/d). Disponível em: <www.bvsde.paho.org/ bvsaidis/ resisoli/peru/brares061.pdf> Acesso em: 19/07/2011.

LAGARES, LUCIANO. Como ajudar a reduzir alagamentos e enchentes?Planeta Sustentável - Revista Vida Simples; Grupo Abril; 11/2007. Disponível em: <http:// planetasustentavel.abril.com.br/noticia/ atitude/conteudo_260146.shtml> Acesso em: 18 jul. 2011.

MONTEIRO, José Henrique Penido; et al. Manual de Gerenciamento Integrado de resíduos sólidos. 15 ed. Rio de Janeiro. Instituto Brasileiro de Administração Municipal - IBAM, 2001.

XAVIER, LÚCIA HELENA, et al. Legislação Ambiental Sobre Destinação de Resíduos Sólidos: 0 Caso das Embalagens Plásticas Pós-consumo. XIII SIMPEP BAURU - $\quad$ SP, $2006 . \quad$ Disponível em: <www.simpep.feb.unesp.br/anais/anais_13/artigos/689.pdf> Acesso em: 21/07/2011 